\title{
On the Semantic Sphere and Linguo-Psychological Essence of Predicative
}

\author{
Turana Guloghlan Mammadova ${ }^{1}$ \\ ${ }^{1}$ Ganja State University, Ganja, Azerbaijan \\ Correspondence: Turana Guloghlan Mammadova, Ganja State University (GSU), Ganja, Azerbaijan. E-mail: \\ turanmammadli1990@gmail.com
}

Received: July 28, 2020 Accepted: August 30, $2020 \quad$ Online Published: September 7, 2020

doi:10.5539/ijel.v10n6p130 URL: https://doi.org/10.5539/ijel.v10n6p130

\begin{abstract}
The present study analyzes the semantic sphere and linguo-psychological essence of the category of predicative. As the scientific basis of the study, the theory of psychological field and the theory of Linguo-Psychological Unity (LPU) is referred to. In accordance with the theory of the psychological field, each concept or frame is in possession of its own semantic sphere. The current study is devoted to the semantic sphere consisting of 1) the nucleus, 2) the nuclear-adjacent zone and 3) the periphery. The grammatical categories of a language also possess their own semantic spheres and the article aims to scrutinize the semantic sphere of the category of predicativity in compliance with psychological nature of a language.

The theory of LPU proves that the form and meaning of linguistic units are abstract concepts formulated by a man himself. Until a unit of reality is fully perceived and given a name, it undergoes threefold generalization or abstraction. While remembering any unit of reality a person makes reference to merely one of these properties or features. This research also provides the explanation of generalization or abstraction by applying various linguistic methods of investigation that will be clarified below. Thus, when information about a unit of reality is saved, it is generalized or abstracted for the first time. Remembering self-contrived features, a person believes and claims that he perceives a unit of reality. Thereby, information about the unit of reality being stored in the main memory is generalized or abstracted for the second time. The unit of reality is not understood as it exists in objective reality and secondly, the name given to it is of a completely arbitrary character. By assigning such an arbitrary name to a unit of reality, the related information stored in the main memory is abstracted for the third time. The theoretical significance of the paper is that the tendency used by us to approach morphological issues from linguo-psychological viewpoint lay the foundation for further study the this trend.
\end{abstract}

Keywords: category, predicative, sphere, morphological, suffix, form

\section{Introduction}

Each philosophical-logical category definitely possesses a determined semantic sphere. The concepts included in this sphere are regarded to be the internal elements of this category. For giving an instance, any numeral, number, or figure is an internal element of a category of quantity, any color, taste or smell is an internal element of a category of quality. Thus, from a semantic point of view, numerals, numbers, and figures are included in the concept of quantity, and color, taste, smell comprise the concept of quality. 


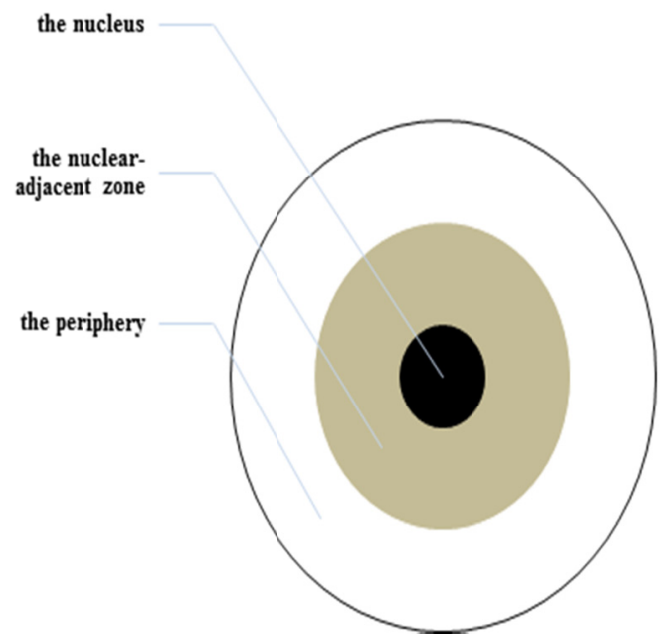

Figure 1. The illustration of the semantic sphere

Accordingly, every lexical and grammatical category existing in a language owns a certain semantic sphere. The semantic sphere of language categories is not as extensive as that of the philosophical-logical categories. Nevertheless, each category existing in a language has its own semantic sphere, the formal indicators forming this sphere and consisting of structural units of language. The semantic sphere belonging to each language category contains: 1) the nucleus, usually expressed in one, and rarely in two or more lexical units, 2) the nuclear-adjacent zone, usually expressed by suffixes, and 3) the periphery reflected in different syntactic units. In Figure 1, the nucleus of the semantic sphere is represented by dark, the nuclear-adjacent zone by a light-colored circle, and the periphery by a colorless circle.

In recent years, an increase in the geometric progression is experienced in the number of studies conducted in linguistics with the application of psychological field theory (Romenech \& Manokha, 2003). On the basis of this theory, the study of various concepts and frames has become relevant to a great extent (Boldirev, 2004, pp. 18-36).

In point of fact, the study of concepts and frames means the determination of the nucleus, the nuclear-adjacent zone and the periphery of the semantic sphere that they possess. In this paper, intention of which is to determine the semantic, morphological and syntactic potential of the category of predicativity, we could simply be satisfied defining the semantic sphere of this category on the basis of field theory. From this point of view, we would present and comment any lexical unit that can be considered as an expression of a predicative as the nucleus of the semantic sphere of this category, the main morphological units making it up as the nuclear-adjacent zone of this sphere, and the concept of predicative formed on the basis of various syntactic structures as the periphery of that semantic sphere, and consequently the problem would be solved. But our goal is not just to specify the semantic sphere of this category. Our main purpose is to reveal the linguo-psychological bases of the unity of meaning and form of language units comprising the category of predicativity on the basis of the recent theories in linguistics, in other words, to determine the semantic, morphological and syntactic potential of the category of predicativity.

\section{Discussions on the Unity of Form and Meaning}

In semiotics, which is regarded as one of the branches of traditional linguistics, as a rule, an attempt is made to study the connection between the form and meaning of lexical units. In fact, this approach, can be considered one of the noteworthy steps taken in terms of defining the linguo-psychological nature of language (Veysalli, 2010). However, research on semiotics does not go beyond the level of lexical units. This field of linguistics does not generally involve the study of structural units belonging to other levels of language, including suffix morphemes or sentence-type structural units. The semiotic direction, based on the dual nature of language units as form and meaning, is advanced enough compared to other areas of linguistics. Nonetheless, semiotics, as we have already mentioned, cannot study language units from all levels, more precisely, non-standard language structural units having a form larger or smaller than lexical units at all. Because it is generally impossible to solve such problems on the basis of classical theoretical foundations that semiotics refers to. 
As Askerov rightly indicates, it is, in fact, the method error to think that the same structural unit of language having a distinct form and a separate meaning that may be distinguished from each other. Correspondingly, the form and meaning of any language unit is an inseparable whole from the linguo-psychological viewpoint (Askerov, 2015, pp. 96-101). Even the slightest change of meaning requires a certain distinction in the previous form or the appearance of a completely new form. (Askerov, 2016, pp. 12-13).

None of the fields of linguistics, including semiotics, that study only language units of lexical level, can give a decisive idea of the minimal variations in the form and meaning of language units. Therefore, the visual identity in the forms associated with the same unit of reality is perceived as complete identity or equality in terms of form and meaning in semiotics and also in morphology and syntax, key sections of modern grammar.

It should be taken into consideration that both the form and the meaning of a language structural unit at any level are abstract notions. Although they reflect reality and are secondary elements or units of reality, they are by no means the very essence of reality or the primary unit of reality. Language structural units are abstract notions related to the unit of reality either in meaning or in form and are products of conventional character formulated by the human brain. (Askerov, 2015, pp. 119-122) As can be seen, all these can be explained from the viewpoint of the theory of Linguo-Psychological Unity (LPU).

\section{Research Methodology}

It is seen that the focus of the study is to scrutinize two main issues: one is related to semantics, the other to linguo-psychology. The preliminary studies may indicate that the category of predicativity may be considered a morphological phenomenon, but in this article, we have aimed to analyze it from the linguo-psychological aspect. For the successful realization of our goal, a number of appropriate methods should be utilized in the course of the research. We have benefitted from various linguistic methods of investigation, which comprise linguistic description, comparative-typological methods and method of semantic and synchronic analysis. Firstly, the linguistic descriptive method has been used in order to depict the abstraction processes of units of realities in the human brain. Since this article investigates semantic sphere of the category of predicativity, the utilization of method of semantic analysis is inevitable. As the article deals with two languages belonging to separate language families of the world, it would be impossible without taking advantage of comparative-typological method. Typological comparative-contrastive method of investigation has been selected for distinguishing predicative suffixes both in Azerbaijani and English languages. And finally, the focus of the synchronic study of a language is to depict certain linguistic phenomena at current period of language development. By means of synchronous approach the concept of predicativity undergoes the analysis from modern linguo-psychological perspective.

\section{Abstraction During Comprehension and Naming}

It is also worth noting that until any unit of reality is perceived by a person and given a name, the information stored in the memory regarding that unit of reality is subjected to abstraction at least three times. The first and second abstractions are observed during the perception of the unit of reality, and the third one in the naming process. Hasanova (2020) in her article underlined that although the comprehension of word is mainly the research objective of psycholinguistics, various ideas related to this problem are encountered also in traditional linguistics. In our opinion, the abstraction of received information in human brain is compatible with her suggestion regarding 3 consequent processes. She has emphasized that the appearance of certain concepts in human thinking consists of the processes of specifying, distinguishing and generalizing significant points of objects or events. In point of fact, this corresponds to the three-time abstraction which we'll study below (Hasanova, 2020, p. 60).

One receives information about all the things, beings, and events of the surrounding world through audio-visual contact, also by touching, tasting, smelling, as well as reading or hearing about them. Let's assume a person, who with the help of the organs of vision, touch, and hearing, learns that a certain object serves to write by leaving a mark on a piece of paper. It means, he sees this item, hears about it, and touches it with his hand. Such contact leads to the perception of this object, which serves to write. However, when a person perceives this object, he does not refer to the color, shape and size he sees with his eyes, nor on the smooth surface, temperature and weight he feels with his hands. Each of these features - signs, or qualities that a person perceives via his senses is a distinctive segment of that unit of reality. But when a person perceives that unit of reality, he refers to only one of these elements. It is precisely through the organs of vision and hearing that a person perceives the information about its function, which he or she accepts as the main feature, remembering it as a "writing instrument". Consequently, the information recorded in his memory about the unit of reality undergoes abstraction for the first time.

It should be taken into account that as a result of such approach, one feature of the unit of reality is considered 
superior as compared to other features and in this way their status of equality in real conditions becomes violated and one of those features is taken into consideration as dominant. For this reason, the aforesaid unit of reality has been understood by a person as a "writing instrument" or "object serving to write". It means, namely this abstract notion of the unit of reality has been recorded and preserved in the main memory. The main reasons for considering the specific feature of the unit of reality dominant may be explained as follows: it is the feature of the comprehended unit of reality that serves a specific human need, is more concise, easier to remember and enables it to be perceived differently from similar units of reality.

For the above-mentioned reason the theory of Linguo-Psychological Unity (LPU) states that it is impossible to fully and completely comprehend reality and its constituent units. Obviously, since reality itself consists of an infinite number of units and the unit of reality has an infinite number of signs and characteristics, it is impossible to fully grasp them.

Only those units of reality are understood by a person that he or she comes into contact with it. Only one or more features of the unit of reality meeting human needs are perceived, that is, information about these features is concisely recorded in the main memory. As it is seen, a person does not fully comprehend the unit of reality. For example, we think that we realize a unit of reality called $a$ book, but we do not know at all what molecules and atoms the paper and the ink on it are made up. We do not even need to know the information about the unit of reality called the book in order to record it in our main memory, or to understand it. We simply save in our main memory an abstract notion relating to the book like "written pages stacked together".

This important aspect or element, which ensures the remembering of the unit of reality, is called the first-order or primary element of reality $\left(\mathrm{ER}_{1}\right)$ according to the theory of Linguo-Psychological Unity (LPU). The same unit of reality possesses other features and elements that are second, third and fourth as compared to the initial one. But the feature or element ensuring the existence of the unit of reality in the main memory is the primary element of reality $\left(\mathrm{ER}_{1}\right)$. It should be noted that $\mathrm{ER}_{1}$ is not always the most important feature of the unit of reality or the most suitable with respect to human needs.

For example, the main peculiarity and the feature meeting human needs of items called duster or eraser, is that they "serve to erase and rub out something". These things have been comprehended by recording these abstract notions (that is $\mathrm{ER}_{1}$ ) in the main memory. In other words, the information existing in our memory about these units of reality is that these things "serve to erase and rub out something".

Sometimes a person perceives a unit of reality on the basis of a feature that does not exist in real life or that is insignificant for the unit of reality itself. The followings may serve as examples: "a kind of poultry with edible meat and eggs" or "a domestic animal with meat and milk suitable as food product". As we read these words, a bird or an animal comes in front of our eyes or we imagine them. Whereas these features are insignificant for the animal or the bird itself. These are the features related to that bird and animal formulated by a person with his own imagination based on his own needs. That means whether a person eats the eggs of these creatures or drinks their milk does not matter to them. Even the absence of one of these features would even be more advantageous for them.

As it is apparent, some units of reality are perceived not on the basis of the qualities that are important to them, but on the basis of false or fake characteristics that have nothing to do with them, but merely meet human requirements. Such facts prove once again that a person himself creates an abstract notion of the unit of reality. A person thinks and claims that he/she understands this unit of reality by memorizing that abstract notion created by him/her. Thus, the unit of reality undergoes abstraction for the second time. It should be noted that there also exist such cases when the information stored in the main memory about the units of reality is neither their main feature nor essential from the viewpoint of any human need.

The third abstraction of information about the unit of reality is observed in the process of naming it, as noted in the theory of Linguo-Psychological Unity (LPU). Even when the ancient Greek philosophers studied the issue of nominating the unit of reality, some of them stated that "the name given to things corresponds to its essence". Other philosophers, on the other hand, argued that "the name given to things is completely arbitrary" and has nothing to do with the essence of the units of reality which they denote (Akhundov, 1979).

In fact, the philosophers representing both of the above-said approaches are equally right. Because the names were given to units of reality such as eraser, duster, refrigerator and etc. indeed correspond to their essence. However, the fact that an astronomer names the newly-discovered star with his own or other person's name proves that some of the names given to units of reality are completely coincidental. In both cases, as M.B. Askerov rightly points out, the name given to the unit of reality is a product of the human brain, being nothing more than an abstract notion formed as a result of his imagination. All these lead to the conclusion that both 
meaning $\left(\mathrm{ER}_{1}\right)$ and form $\left(\mathrm{ER}_{2}\right)$ belonging to a language structural unit at any level are abstract ideas and products of the human brain. In other words, as stated by Hasanova, "a person perceives the world through the prism of his/her subjective experiences. From the psychological viewpoint, the comprehension of word by a person is the unity of generalization, communication and thinking processes" (Hasanova, 2020, p. 61). Taking the above-mentioned into account we think that trying to separate the form and meaning of a language structural unit from any level, or to consider them separately is a methodological mistake. Having approached this issue in a different way, Woensdregt and Smith (2017) examine abstraction from a pragmatic viewpoint and define that the act of communication consists of coding and decoding processes between the signaler and the receiver (Woensdregt \& Smith, 2017, p. 4).

\section{The Nucleus of the Category of Predicativity}

In most world languages, the structural units of language that formulate the category of predicativity possess a grammatical suffix form or syntactic pattern as a rule. These suffixes have distinct variants in different languages, for example, in the Azerbaijani language these suffixes are used in the following variants for different persons

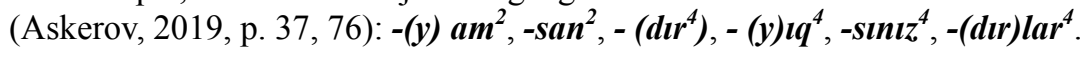

On one hand, each form of these suffix variants in Azerbaijani has various shades of meaning belonging to different persons. On the other hand, there is a common semanteme that is identical or similar to all of these suffixes and for all persons.

The variability in semantemes of the predicative suffixes may be explained by the fact that the suffix variant used in connection with each person makes the added word belong to a completely different person, for example:

Table 1. Sentence patterns in the singular form

\begin{tabular}{lll}
\hline Persons in singular & Sentences in Azerbaijani & Sentences in English \\
\hline 1st person singular & Man talabəyəm or Mən yazıram & I am a student or I write \\
2nd person singular & San talabəsən or Sən yazırsan & You are a student or You write \\
3rd person singular & Otalabədir or O yazır & He is a student or He writes \\
\hline
\end{tabular}

Table 2. Sentence patterns in the plural form

\begin{tabular}{lll}
\hline Persons in plural & Sentences in Azerbaijani & Sentences in English \\
\hline 1st person plural & Biz talabəyik or Biz yazırıq & We are students or We write \\
2nd person plural & Siz talabəsiniz or Siz yazırsinız & You are students or You write \\
3rd person plural & Onlar tolabədirlor or Onlar yazırlar & They are students or They write \\
\hline
\end{tabular}

The common meaning or semanteme of these suffix variants for all persons is their ability to provide the words with the meanings of "completeness" or "integrity" and consequently convert them into predicate either independently or within the sentence. In other words, the words having predicative suffix acquire the essence and status of independent utterance dependent on this suffix. In this case the shades of "completeness" or "integrity" possessed by the forms of predicative simply affect the meaning of that word-utterance.

If a word with this suffix is used within a sentence alongside with other syntactically related words and phrases, then the shades of "completeness" or "integrity" affect not only the meaning of the word, but also the general context of the whole utterance in which it is used, provided that the word is the dominant element.

It should be taken into consideration that a grammatical category is a cluster or combination of grammatical forms with the same and similar shades of meaning. Based on this, we can state with certainty that the shade of meaning that plays a key role in the formation of the category of predicativity is not a semanteme expressing different persons in these forms, but a semanteme imparting a shade of "completeness" or "integrity" to all words or utterances. This idea leads to the conclusion that the shades of "completeness" or "integrity" are the principal shades of meaning that play a decisive role in the formation of the category of predicativity. In fact, this principal proposition also puts an end to the different opinions and debates put forward by different linguists and researchers regarding the name of this category. That is to say, this deduction evinces once again that denominating the category involved in the research not the category of person, but the category of predicativity, is more expedient and precise.

The category of predicativity, or its means of expression, at the same time means the suffixes which directly formulate this form, as well as all the other suffixes utilized in the forms of predicativity. In other words, the 
category comprises suffixes of nominal and verbal predicate on the one hand, and all other suffixes found in nominal and verbal predicate forms on the other hand. From this point of view, not only these, but even all finite forms of the verb can be considered as means of expression of the category of predicativity. Even in Azerbaijani it is possible to present and interpret nominal predicate as the nucleus of the semantic sphere of this category, the indicative mood as the nuclear-adjacent zone, other suffixes not playing any significant role, but participating in the formation of different predicate forms as the periphery of this semantic sphere.

It should also be taken into account that simply memorizing suffix-type language units does not suffice to use them accurately, correctly and in their proper position in the speech process. Together with the form and pattern of this language unit, it is necessary to notice its semanteme and sequence. It means, in addition to the meaning of each suffix-type language structural unit, one should obtain knowledge about the order of arrangement of these suffixes. For example, in English, negative and interrogative-negative forms of the present simple tense form are made up of the same forms used in different sequences. In connection with this issue Khan (2011) in his article investigated the hardships of learning English in terms of tense forms, as well as usage of auxiliary verbs for Arabian learners. According to him, "Learners of English are supposed to find it difficult to manipulate the various ways in which English uses the first auxiliary verb of a tense. Here includes negation (e.g., He hasn't been drinking.), inversion with the subject to form a question (e.g., Has he been drinking?), short answers (e.g. Yes, he has.) and tag questions (has he?)." (Khan, 2011, p. 109)

Those intending to master English cannot construct the negative and interrogative-negative forms without knowing this sequence:

Table 3. Sentence patterns in both languages

\begin{tabular}{lll}
\hline Sentence types & Sentence patterns in English & Sentence patterns in Azerbaijani \\
\hline Affirmative form & I read./ He runs. & Mən oxuyuram./ O qaçır. \\
Negative form & I don't read./ He doesn't run. & Mən oxumuram./O qaçmır. \\
Interrogative-negative form & Don't I read?/ Doesn't he run? & Mən oxumurammı?/O qaçmırmı? \\
\hline
\end{tabular}

A. Radford, who has extensively studied the use of auxiliary verbs in interrogative and negative forms, as well as their use in other grammatical forms, believes that according to their syntactic properties auxiliaries constitute a different category from verbs (Radford, 2004, p. 27). But from our perspective, it would be impossible to imagine verb and its tense, voice, mood categories, without any auxiliary verb.

The order of suffixes is extremely important for agglutinative languages, including Azerbaijani. In the example above, if we change the order of the suffixes used in the form "oxu-mur-am-mı", this form will become meaningless:

"oxu-mur-am-mı"; "oxи-am-mur-mı"; "oxи-mı-mur-am"; "oxи-mur-ml-am" etc.

These cases prove once again that each language structural unit, including the category of predicativity we are talking about, is a linguistic-psychological phenomenon consisting of a combination of form $\left(\mathrm{ER}_{2}\right)$ and meaning $\left(E R_{1}\right)$, and has a specific sequence and position within the speech utterance.

\section{Conclusions.}

In the article, as the result of investigating various issues related to semantic, morphological and syntactic potential of predicativity, as well as the names and linguo-psychological nature of the suffixes making up the nominal and verbal predicate we have come to the following conclusions:

1) We consider it illogical to name structural units of language with different terms, which are completely same and identical in terms of both form and semanteme. For clarifying this, some name the above-mentioned suffix a "personal suffix" and others a "predicative suffix", accordingly a grammatical category consisting of the same forms, once is regarded as "the category of person" and in other case "the category of predicative". The chaos created by this terminological misunderstanding during language studies is enough to reject this approach. In our opinion, it may be more accurate in case of naming the forms or suffixes of both nominal and verbal predicates as "predicative forms or suffixes", and the category consisting of them as "the category of predicative", and think that this term is more precise and useful in teaching the language either to native speakers or foreigners.

2) When we state the predicative form or the category of predicative, we indicate the form and category that directly makes up the nominal or verbal predicate and ensures its formation. While speaking about its means of expression we consider predicative suffixes - the nucleus of semantic sphere of this category; all forms of 
indicative mood-its nuclear-adjacent zone; suffixes, forms and patterns involved directly or indirectly in the formation of any kind of predicate - the periphery of this semantic sphere.

3) Information about the unit of reality is abstracted at least three times until it is comprehended and the information about it is recorded in the main memory, as well as until this unit of reality is given a name and added to the code of intellect belonging to that unit of reality: the first abstraction is observed when one of the several features of a unit of reality has been selected as the main feature of it; the second abstraction is noticed when a false, fake aspect or feature non-inherent to the unit of reality is accepted as the main feature by human imagination; the third abstraction happens when a unit of reality is denominated by a person.

\section{References}

Akhundov, A. A. (1979). General Linguistics. Baku: Maarif.

Askerov, M. B. (2015). The Theory of Linguo-Psychological Unity. Baku: Elm ve tehsil.

Askerov, M. B. (2016). Program on general linguistics. For bachelor's degree in higher education. Baku: Diplomat

Askerov, М. В. (2019). “Салам, Азербайджан!” A-1 - Beginner level (grammar rules, exercises, thematic dictionaries) (in Russ.). Baku: Elm.

Boldirev, N. N. (2004). Conceptual space of cognitive linguistics (in Russ.) Вопросы когнитивной лингвистики, 1, 18-36.

Hasanova, A. S. (2020). Basic Factors Motivating the Extension of Word Meaning. International Journal of English Linguistics, 10(5), 60-67, https://doi.org/10.5539/ijel.v10n5p60

Khan, I. A. (2011). Role of Applied Linguistics in the Teaching of English in Saudi Arabia. International Journal of English Linguistics, 1(1), 105-114. https://doi.org/10.5539/ijel.v1n1p105

Radford, A. (2004) English Syntax: An Introduction. Cambridge University Press, Cambridge, ISBN 0521 542758 (paperback).

Romenech, V. A., \& Manokha, I. P. (2003). The history of psychology of the 20 century (in Russ.) Kiev, Libid, for more on "Psychological field theory" of Kurt Levin.

Veysalli, F. Y. (2010). Semiotica. Studia Philologica (vol. 6). Baku: Mutarjim.

Woensdregt, M., \& Smith, K. (2017). Pragmatics and Language Evolution. Oxford Research Encyclopedia of Linguistics, 5/16, Online Publication 2017. https://doi.org/10.1093/acrefore/9780199384655.013.321

\section{Copyrights}

Copyright for this article is retained by the author, with first publication rights granted to the journal.

This is an open-access article distributed under the terms and conditions of the Creative Commons Attribution license (http://creativecommons.org/licenses/by/4.0/). 